\title{
ESTUDO COMPARATIVO DOS CURRÍCULOS DOS CURSOS DE BIBLIOTECONOMIA NO BRASIL
}

\author{
COMPARATIVE STUDY OF SYLLABUS OF \\ LIBRARIANSHIP COURSES IN BRAZIL
}

\author{
Camila Monteiro de Barrosa \\ Miriam Vieira da Cunhab \\ Lígia Maria Arruda Caféc
}

\begin{abstract}
RESUMO
Introdução: A sociedade se constitui num movimento orgânico em suas diversas dimensões - cultural, profissional, educacional, etc. - assim, é imprescindível que os currículos dos cursos de Biblioteconomia sejam repensados e ressignificados a partir dessa evolução social. Objetivo: Esse estudo tem como objetivo levantar informações a respeito da estrutura curricular dos cursos de Biblioteconomia das universidades brasileiras como forma de desenvolver um panorama da situação atual desses cursos. Metodologia: Inicialmente, foram selecionados os 26 cursos de universidades federais e estaduais brasileiras, no entanto, consideramos apenas as nove universidades que disponibilizavam em seus sites as informações necessárias para o estudo. Os currículos foram analisados a partir das áreas curriculares propostas para os cursos de Biblioteconomia dos países do Mercosul. Resultados: Constatamos que a área que apresenta maior carga-horária de disciplinas obrigatórias é a de Formação Geral, com $16,56 \%$. A área com menor representatividade é a de Tecnologias da Informação, com $5,94 \%$. Verificamos também que a distribuição de carga horária em cada área curricular é bem variada, a partir dos diferentes contextos das universidades analisadas. Conclusão: Nesse sentido, apontamos a necessidade de não pensar o currículo de forma demasiado individualizada. Para tanto, é sensato estar a par das demandas sociais tanto para atender à realidade atual quanto para modificá-la.
\end{abstract}

Descritores: Biblioteconomia. Estrutura curricular. Brasil.

\footnotetext{
a Doutora em Ciência da Informação pela Universidade Federal de Santa Catarina. Professora da Universidade Federal de Santa Catarina (UFSC). E-mail:

b Doutora em Informação científica e técnica pelo Conservatoire National des Arts et Metiers de Paris. Professora da Universidade Federal de Santa Catarina (UFSC).

c Doutora em Linguística pela Université Laval do Canadá. Professora da Universidade Federal de Santa Catarina (UFSC).
} 


\section{INTRODUÇÃO}

A tarefa de refletir a respeito da constituição dos currículos do curso de Biblioteconomia do Brasil perpassa pela reflexão dos objetivos do ensino superior e do necessário diálogo entre as esferas social, profissional e governamental. Existem demandas sociais que precisam ser atendidas por indivíduos com conhecimento e competência para tal, em novos espaços de trabalho do bibliotecário. Daí decorremos traços fundamentais que direcionam o desenvolvimento do plano de formação deste profissional no ensino superior. Por um lado, essa formação deve ser capaz de dar ao bibliotecário conhecimento e competência para atender as demandas da sociedade. Por outro, não se pode prescindir de um estado de vigília, por assim dizer, para que a formação desse profissional não fique destinada unicamente àsua adequação às demandas mercadológicas e manutenção do contexto atual. Segundo Rodrigues (2002, p. 14), a educação superior deve ser aquela que "não atenda apenas às demandas do mercado, mas, que sem desconsiderá-las, esteja fundamentalmente comprometida com a formação de um cidadão imbuído de valores éticos." Assim, essas demandas são também entendidas como indicações de possíveis mudanças que precisam ser instaladas e que se darão por meio da formação de um bibliotecário capaz de perceber e atuar criticamente.

Pensar a respeito dos elementos que devem concorrer para a formação de um profissional é um movimento evolutivo, em constante revisão, que não pode parar (no tempo). Em outras palavras, o perfil profissional corresponde à visão daquilo que a sociedade espera dele em determinado momento. Como a sociedade está em permanente modificação, afetada por novas (ou velhas) políticas ou por diferentes conformações sociais, o retrato do profissional oferecido a esta sociedade deve acompanhar este processo e se adequar a ela. Assim, o movimento de revisão dos currículos do ensino superior ocorre na tentativa de buscar a harmonização do perfil profissional com as demandas sociais, tanto no sentido de atendê-las quanto no sentido de agir para a modificação do entorno social. Neste sentido, o currículo das diferentes escolas profissionais deve estar em sintonia com as demandas dessa sociedade. 
Na realidade, a estrutura cognitiva de cada profissão deve ser legitimada pela sociedade. A formação profissional garante à sociedade o monopólio do conhecimento em uma área definida, dando acesso à qualificação e ao reconhecimento da profissão. Esta sociedade, por sua vez, dá à profissão 0 direito exclusivo do exercício em uma área específica do mundo do trabalho. Essa legitimação se fortalece à medida que profissionais capacitados atuam no mercado demonstrando competência e levando, por sua vez, ao crescimento do seu espaço de atuação (CUNHA, 2013).

No que concerne à estrutura curricular dos cursos de Biblioteconomia, a comunicação entre sociedade, governo e universidade precisa ocorrer por meio das associações de classe, que têm (ou deveriam ter) relevância primordial na percepção dos aspectos inerentes à profissão que representam, atuando como interlocutores dessas necessidades.

A Associação Brasileira de Ensino de Biblioteconomia e Documentação (ABEBD) - criada em 1967 e extinta no início de 2001, teve seu trabalho continuado pela Associação Brasileira de Educação em Ciência da Informação (ABECIN), criada nesse mesmo ano. A ABECIN teve uma participação politicamente relevante nas mudanças do ensino de Biblioteconomia no Brasil nas últimas décadas (SOUZA, 2011). No entanto, cabe registrar o distanciamento das Associações de Bibliotecários dos debates sobre as demandas necessárias à formação do bibliotecário, já que essas associações são representantes desses profissionais no mundo do trabalho.

A criação da ABEBD constituiu importante espaço de discussão a respeito do ensino de Biblioteconomia no país, especialmente no período em que os cursos de Biblioteconomia eram regidos pelo Currículo Mínimo estabelecido pelo Conselho Federal de Educação primeiramente em 1962 e depois em 1982, após proposta de mudança curricular apresentada pela ABEBD (CASTRO, 2002).

Em 1996, coma implantação da nova Lei de Diretrizes e Bases da Educação (LDB) (BRASIL, 1996) a noção de Currículo Mínimo foi substituída pela elaboração de um Projeto Pedagógico a ser embasado em Diretrizes Curriculares Nacionais (DCN). Essas diretrizes "devem orientar a formulação 
do projeto pedagógico dos cursos" e esse projeto deve explicitar: o perfil dos formandos; as competências e habilidades gerais e específicas a serem desenvolvidas; os conteúdos curriculares de formação geral e os conteúdos de formação específica ou profissionalizante; o formato dos estágios; as características das atividades complementares; a estrutura do curso e as formas de avaliação (CONSELHO NACIONAL DE EDUCAÇÃO, 2001).

As Diretrizes Curriculares foram elaboradas com a participação de Comissões de Especialistas para cada área de conhecimento e homologadas em 2001. No que se refere à área de Biblioteconomia, os conteúdos de formação são divididos em gerais e específicos ou profissionalizantes. Essas normas recomendam acentuar a adoção de uma "perspectiva humanística na formulação dos conteúdos, conferindo-lhes um sentido social e cultural que ultrapasse os aspectos utilitários mais imediatos sugeridos por determinados itens" (CONSELHO NACIONAL DE EDUCAÇÃO, 2001, p. 33). Essa configuração evidencia claramente a flexibilidade das escolas de Biblioteconomia para reformular seus currículos.

Guimarães (2002) relata que outro aspecto relevante ocorrido em 1996 foi a realização do I Encuentro de Directores de Escuelas Universitarias de Bibliotecologia del Mercosur, em Porto Alegre, por iniciativa da ABEBD. Tal evento foi levado a cabo após a inserção dessa Associação no Programa II do Plano para o Desenvolvimento Educativo Regional dos países do Mercosul. O principal resultado deste encontro foi a proposta de harmonização dos currículos dos cursos de Biblioteconomia do Mercosul. No II Encuentro de Directores de Escuelas Universitarias de Bibliotecologia del Mercosur realizado em 1997 na cidade de Buenos Aires, foram definidas 6 áreas curriculares sendo que "o primeiro estudo da Comissão de Especialistas resgatou uma estrutura de área quase idêntica à proposta para o Mercosul" (GUIMARÃES, 2002, p. 65), conforme quadro abaixo: 
Quadro 1 - Áreas curriculares da Biblioteconomia Diretrizes Curriculares MEC/SESu

Fundamentos de Biblioteconomia Proposta Mercosul

Organização e Tratamento da Informação Fundamentos de Biblioteconomia e Ciência da Informação

Gestão da Informação e do

Conhecimento

Políticas de Gestão de Unidades de Informação Recursos e Serviços de Informação Tecnologias em Informação Metodologia da Pesquisa Organização e Tratamento da Informação Fonte: Guimarães (2002, p. 65)

Essas áreas, quando relacionadas às DCN, se referem aos conteúdos de formação específica.

De 2002 a 2005, a ABECIN prestou precioso apoio aos cursos de Biblioteconomia em todo país no processo de revisão de seus planos pedagógicos cujas áreas curriculares definidas para os países do Mercosul continuam sendo a referência das discussões nesse âmbito (RODRIGUES; CUNHA, 2007).

Apesar da necessária flexibilidade das instituições para sua estruturação curricular regionalizada - tanto na definição dos conteúdos e disciplinas quanto nas formas de integração entre graduação e pós-graduação, entre universidade e sociedade e entre formação profissional e pesquisa - o diálogo estabelecido entre os cursos de Biblioteconomia do Brasil e dos outros países do Mercosul, que se realizam periodicamente (1996, Porto Alegre; 1997, Buenos Aires; 1998, Santiago; 2000, Montevideo; 2001, Assunção, 2002, Londrina; 2004, Mar del Plata; 2005, Montevideo: 2007, Valparaíso; 2012, Montevidéo; 2014, Buenos Aires) tem levado à adoção de diretivas comuns contribuindo para a construção de um entendimento mais sólido da posição política, social e econômica da profissão. Além disso, esse debate coletivo vem resultando no amadurecimento e desenvolvimento da formação do bibliotecário. Dessa forma, os conteúdos curriculares para a formação de um profissional atento às especificidades da sua região não devem resultar em um perfil demasiado específico a ponto de impedir o fluxo dos profissionais entre diferentes regiões. 
Considerando-se o movimento orgânico da sociedade em suas diversas dimensões, é imprescindível que os currículos dos cursos sejam repensados e ressignificados a partir dessa evolução. Esse estudo tem como objetivo levantar informações a respeito da estrutura curricular dos cursos de Biblioteconomia das universidades brasileiras como forma de desenvolver um panorama da situação atual desses cursos.

\section{PROCEDIMENTOS METODOLÓGICOS}

O levantamento de dados foi realizado em três etapas. Na primeira etapa, foram identificadas as instituições que oferecem cursos de Biblioteconomia presenciais no Brasil. Esse levantamento foi realizado por meio das informações disponíveis no site do $\mathrm{MEC}^{d}$ sobre as instituições credenciadas. Segundo esse site, existem no nosso país 39 cursos de Biblioteconomia. Na segunda etapa, foram selecionados os cursos das universidades federais e estaduais, sendo excluídos os das demais instituições resultando em 26 cursos (anexo). Essa seleção foi feita porque os cursos das universidades públicas, como tem sido evidenciado em avaliações como as realizadas periodicamente pelo Instituto Nacional de Estudos e Pesquisas Educacionais Anísio Teixeira (INEP) e pelo Guia do Estudante, destacam-se como os melhores do país.

A terceira etapa foi dedicada ao levantamento das informações dos currículos das universidades. Para tanto, acessamos o site de cada uma delas em busca do Plano Político Pedagógico, grade curricular e ementas das disciplinas obrigatórias dos cursos de Biblioteconomia. No período da coleta de dados (janeiro/2014) não conseguimos acessar o site do curso de 3 universidades (UNB, UESPI e UNIR);10 universidades apresentavam apenas as grades curriculares (FURG, UNIRIO, UFMG, UFMT, UFS, UFPB, UFRN, UFC, UFAM, UEL); 13 universidades disponibilizavam a grade curricular e as ementas das disciplinas. No entanto, dessas 13 universidades, 4 não apresentavam a carga-horária total do curso (UFG, UFBA, UFPA, UFES).

\footnotetext{
d Disponível em: <http://emec.mec.gov.br/>
} 
Nesse sentido, esse estudo considerou apenas as 9 universidades que disponibilizavam em seus sites as informações necessárias para o estudo, conforme quadro abaixo.

Quadro 2 - Universidades consideradas para o estudo

\begin{tabular}{|c|c|c|c|c|}
\hline Região & & Universidade & Nome do curso & Site do curso \\
\hline \multirow{3}{*}{ Sul } & UFSC & Universidade Federal de Santa Catarina & Biblioteconomia & $\begin{array}{l}\text { http://cin.ced.ufsc.br/curso-de- } \\
\text { graduacao-em-biblioteconomia/ }\end{array}$ \\
\hline & UFRGS & Universidade Federal do Rio Grande do Sul & Biblioteconomia & $\begin{array}{l}\text { http://www.ufrgs.br/fabico/Gra/b } \\
\text { iblioteconomia-1 }\end{array}$ \\
\hline & UDESC & Universidade do Estado de Santa Catarina & Biblioteconomia & $\begin{array}{l}\text { http://www.faed.udesc.br/?id=1 } \\
08\end{array}$ \\
\hline \multirow{3}{*}{ Sudeste } & USP & Universidade de São Paulo & Biblioteconomia* & $\begin{array}{l}\text { https://uspdigital.usp.br/jupiterw } \\
\text { eb/listarGradeCurricular?codcg } \\
=27 \& \text { codcur }=27501 \& \text { codhab }=4 \\
\text { \&tipo=N }\end{array}$ \\
\hline & UNESP & $\begin{array}{l}\text { Universidade Estadual Paulista Júlio de Mesquita } \\
\text { Filho }\end{array}$ & Biblioteconomia & $\begin{array}{l}\text { http://www.marilia.unesp.br/\#!/g } \\
\text { raduacao/cursos/biblioteconomi } \\
\text { a/ }\end{array}$ \\
\hline & UFSCAR & Universidade Federal de São Carlos & $\begin{array}{l}\text { Biblioteconomia e } \\
\text { Ciência da Informação }\end{array}$ & $\begin{array}{l}\text { http://blogbciufscar.blogspot.co } \\
\text { m.br/ }\end{array}$ \\
\hline \multirow{3}{*}{ Nordeste } & UFAL & Universidade Federal de Alagoas & Biblioteconomia & $\begin{array}{l}\text { http://www.ichca.ufal.br/gradua } \\
\text { cao/biblioteconomia/v1/ }\end{array}$ \\
\hline & UFPE & Universidade Federal de Pernambuco & Biblioteconomia & $\begin{array}{l}\text { http://biblioteconomiaufpe.word } \\
\text { press.com/ }\end{array}$ \\
\hline & UFMA & Universidade Federal do Maranhão & Biblioteconomia & $\begin{array}{l}\text { http://www.biblioteconomia.ufm } \\
\text { a.br/curso/ }\end{array}$ \\
\hline
\end{tabular}

* Oferece o curso no período diurno e noturno. Para a pesquisa, consideramos o curso do período noturno.

Fonte: Dados da pesquisa, 2014

Para o tratamento dos dados utilizamos uma planilha elaborada no programa Excel, tendo-se como base as seis áreas curriculares propostas para o Mercosul. Considerando-se que este estudo tem a finalidade de comparar diversos currículos e não desenvolver um currículo específico, incluímos uma área de formação geral e uma dedicada à atividade de estágio. Abaixo apresentamos uma breve caracterização de cada área curricular, baseada nas concepções apresentadas no apêndice 1 do trabalho de Souza (2011) e em Guimarães (2002).

1) Fundamentos de Biblioteconomia e Ciência da Informação: compreende temas que amparam a compreensão da perspectiva histórica da área e da profissão do bibliotecário, como a história dos meios de comunicação, história das bibliotecas, ética e políticas de informação.

2) Organização e Tratamento da Informação: engloba as disciplinas relacionadas aos tópicos de descrição física e temática da informação, bem como a prática da aplicação de códigos, sistemas de organização do conhecimento e normas.

3) Gestão de Unidades de Informação: abrange as funções administrativas (planejamento, organização, controle e avaliação), a gestão do marketing, de recursos e de qualidade aplicadas ao contexto das unidades de informação. Excluem-se, portanto, 
disciplinas de fundamentos em Administração (como introdução, TGA, etc.). Também inclui a gestão do acervo (desenvolvimento de coleções e conservação), editoração e o estudo de tipos específicos de bibliotecas.

4) Recursos e Serviços de Informação: envolve o desenvolvimento e aplicação de serviços de informação abrangendo o estudo e educação de usuários, fontes de informação, recuperação da informação, serviço de referência e serviços de extensão e ação cultural.

5) Tecnologias da Informação: abarca o aparato tecnológico aplicável à atividade, como o desenvolvimento e operação de bases de dados, bibliotecas digitais, automação de unidades de informação e conhecimentos em informática de caráter introdutório ou avançado.

6) Pesquisa: engloba o estudo teórico e prático dos métodos, teorias e procedimentos de pesquisa incluindo também estatística, o desenvolvimento do TCC e normalização da documentação.

7) Formação geral:compreende disciplinas instrumentais e de caráter geral relacionadas às áreas afins da Biblioteconomia como teoria geral da Administração, Antropologia, Comunicação, Filosofia, História do Brasil, Inglês instrumental, entre outras.

8) Estágio: abrange seminários e práticas de estágio.

As disciplinas obrigatórias do curso de Biblioteconomia de cada universidade e as respectivas ementas foram inseridas na planilha do Excel sendo agrupadas conforme as áreas estabelecidas.

É relevante registrar que as grades curriculares são organizadas, na sua maior parte, por fase do curso e não por área de conhecimento. Em 6 casos foi possível ter acesso ao Plano Político Pedagógico do curso (UFAL, UFMA, UFPE, UNESP, UFSC, UDESC). Esses cursos apresentavam o agrupamento por áreas, servindo como parâmetro para a análise das disciplinas. Nos demais casos, para identificar cada disciplina com uma área, o critério de classificação foi o conteúdo exposto nas ementas das mesmas. Dessa forma, tal classificação ficou sujeita à subjetividade do entendimento que se teve de cada disciplina.

Deve-se ainda considerar que se trata de disciplinas de diferentes áreas de especialidade (tecnologia, gestão, processos técnicos, fundamentos, etc.), com denominações e objetivos diversos. Qualquer tipo de classificação nunca é neutra ou universal, mas pode ter um alto grau de aceitação desde que elaborada com base no compartilhamento e no debate aberto e coletivo. Assim, 
essa classificação é um parâmetro inicial para o desenvolvimento do estudo, entendendo-se que sua pertinência deve ser validada com a participação da coletividade interessada.

A análise dos dados foi realizada de forma quantitativa possibilitando a identificação de um panorama geral da situação atual de cada curso de Biblioteconomia no Brasil. Em próxima fase desse estudo, os currículos poderão ser analisados na perspectiva qualitativa.

\section{RESULTADOS}

Segundo as Diretrizes Curriculares Nacionais para os cursos de Biblioteconomia, o conteúdo curricular de formação geral e de formação específica é integralizado com a realização de estágio e de atividades complementares como monitoria, participação em congressos, etc. Neste estudo, a carga horária referente ao estágio foi contabilizada dentro das disciplinas obrigatórias. A carga-horária mínima estabelecida pelo Conselho Nacional de Educação para os cursos de Biblioteconomia é de 2400 horas, incluindo o estágio e as atividades complementares.

A tabela 1 mostra a porcentagem de carga horária (c/h) ocupada pelas disciplinas obrigatórias dentro da carga total de cada curso de Biblioteconomia.

Tabela 1 - Carga horária total dos cursos de Biblioteconomia e das disciplinas obrigatórias

\begin{tabular}{lccc}
\hline C/h total do curso & $\begin{array}{c}\text { C/h total em disciplinas } \\
\text { obrigatórias }\end{array}$ & $\begin{array}{c}\text { \%da c/h em disciplinas } \\
\text { obrigatórias }\end{array}$ \\
\hline UFSC & 2826 & 2634 & 93.21 \\
UFRGS & 2850 & 2220 & 77,89 \\
UDESC & 3222 & 2880 & 89.39 \\
USP & 3060 & 2670 & 87.25 \\
UNESP & 2670 & 2280 & 85,39 \\
UFSCAR & 2880 & 2220 & 77.08 \\
UFAL & 2900 & 2280 & 78.62 \\
UFPE & 2450 & 1950 & 79.59 \\
UFMA & 2850 & 2760 & 96.84 \\
\hline \multicolumn{1}{c}{ Média } & $\mathbf{2 8 5 6}$ & $\mathbf{2 4 3 2}$ & $\mathbf{8 8}$ \\
\hline
\end{tabular}

Fonte: Dados da pesquisa, 2014

Inf. Inf Londrina, v. 23, n. 1, p. 290 - 310, jan./abr. 2018

http://www.uel.br/revistas/informacao/ 
A tabela 1 mostra que a UFSCAR tem o menor percentual de disciplinas obrigatórias $(77.08 \%)$, tendo, $660 \mathrm{~h}$ em atividades complementares e/ou disciplinas optativas. Já a UFMA tem o maior percentual (96.84\%), tendo, portanto, apenas $90 \mathrm{~h}$ em atividades complementares e/ou disciplinas optativas.

Esses números traduzem uma maior ou menor flexibilidade do currículo do curso para que o aluno oriente sua própria formação. É importante registrar que, dada a falta de informação em diversos sites, não foi possível conhecer com precisão as atividades complementares.

Vale ressaltar que as atividades complementares a serem inseridas no currículo dependem também da oferta de eventos e congressos na área e da possibilidade do aluno se deslocar até esses eventos, dependendo da região onde ocorrem. Também podemos pensar que as disciplinas optativas devem ser de interesse dos alunos e atender às demandas do curso, do contrário, a carga horária complementar perde seu objetivo de contribuir na formação.

$\mathrm{Na}$ tabela 2 estão expostos os percentuais de carga horária das disciplinas obrigatórias em cada área curricular.

Tabela 2 - Carga horária em disciplinas obrigatórias em cada área curricular dos cursos de Biblioteconomia com relação à c/h total do curso.

\begin{tabular}{|c|c|c|c|c|c|c|c|c|c|c|}
\hline & UFSC & UFRGS & UDESC & USP & UNESP & UFSCAR & UFAL & UFPE & UFMA & Média \\
\hline ÁREAS CURRICULARES & $\%$ & $\%$ & $\%$ & $\%$ & $\%$ & $\%$ & $\%$ & $\%$ & $\%$ & $\%$ \\
\hline $\begin{array}{l}\text { Fundamentos teóricos } \\
\text { da Biblioteconomia e da } \\
\text { Ciência da Informação }\end{array}$ & 6.37 & 8,42 & 3.91 & 4.90 & 6.74 & .17 & 9.66 & 9.80 & 8.42 & 7,01 \\
\hline $\begin{array}{l}\text { Organização e } \\
\text { tratamento da } \\
\text { informação }\end{array}$ & 17.83 & 11,58 & 13.97 & 18.63 & 15.73 & 16.67 & 12.41 & 17.14 & 12.63 & 15,25 \\
\hline $\begin{array}{l}\text { Gestão de Unidades de } \\
\text { Informação }\end{array}$ & 15.29 & 11,05 & 15.64 & 7.84 & 7.87 & 10.42 & 11.72 & 15.92 & 16.84 & 13,06 \\
\hline $\begin{array}{l}\text { Recursos e Serviços de } \\
\text { Informação }\end{array}$ & 15.29 & 8,42 & 10.61 & 5.88 & 7.87 & .25 & 8.28 & 7.35 & 8.42 & 9,59 \\
\hline $\begin{array}{l}\text { Tecnologias da } \\
\text { Informação }\end{array}$ & 2.55 & 4,21 & 11.17 & 2.94 & 7,86 & 10.42 & 8.97 & 4.90 & 6.32 & 5,94 \\
\hline Pesquisa & 14.01 & 18,42 & 12.85 & 11.76 & 15.73 & 12.50 & 6.90 & 11.02 & 13.68 & 12,02 \\
\hline Formação geral & 12.31 & 6,32 & 10.06 & 22.55 & 14.61 & 6.25 & 12.41 & 1.22 & 21.05 & 16,56 \\
\hline Estágio & 9.55 & 9,47 & 11.17 & 12.75 & 8.99 & 10.42 & 8.28 & 12.24 & 9.47 & 10,21 \\
\hline
\end{tabular}

Fonte: Dados da pesquisa, 2014

Inf. Inf Londrina, v. 23, n. 1, p. 290 - 310, jan./abr. 2018.

http://www.uel.br/revistas/informacao/ 
Os dados das tabelas mostram uma grande variação na distribuição das disciplinas por área curricular.

Como é possível verificar na tabela 2, a UDESC tem o menor percentual de horas na área de Fundamentos Teóricos da Biblioteconomia e da Ciência da Informação $(3,91 \%)$ e a UFPE, o maior percentual $(9,80 \%)$. Nessa área foi recorrente a presença de disciplinas de caráter introdutório em Biblioteconomia e Ciência da Informação, sendo que nos cursos da UFSC e UFPE essas disciplinas se apresentam como especificamente voltadas à área de Biblioteconomia: na UFSC, "Fundamentos de Biblioteconomia" e na UFPE, "Biblioteconomia e Pensamento Científico" e também "Fundamentos de Biblioteconomia". Em algumas universidades, ocorre uma menção à área de Ciência da Informação além da Biblioteconomia, por exemplo: na UFAL, UDESC e UFSCAR, "Introdução à Biblioteconomia e à Ciência da Informação"; na USP, "Fundamentos em Biblioteconomia, Documentação e Ciência da Informação". Em outros cursos são oferecidas disciplinas específicas de Biblioteconomia e específicas de Ciência da Informação, como por exemplo: na UFMA, "Fundamentos de Biblioteconomia" e "Princípios de Ciência da Informação"; na UNESP: "Introdução à Ciência da Informação" e "Introdução à Biblioteconomia". Essas variações na abordagem da Biblioteconomia e da Ciência da Informação transparecem uma falta de consenso na relação que se estabelece entre essas duas áreas.

Todos os cursos contam com disciplinas que abordam a perspectiva histórica dos registros do conhecimento e/ou das bibliotecas. Entretanto, o que chama a atenção é que apenas os cursos UFSC e UFRGS têm disciplinas relacionadas à ética como obrigatórias. Na realidade, apesar da importância da ética no fazer de qualquer profissional e de recomendação do Conselho Federal de Biblioteconomia nesse sentido (CONSELHO FEDERAL DE BIBLIOTECONOMIA, 1976) os cursos não dão a devida importância a essa disciplina.

$\mathrm{Na}$ área de Organização e Tratamento da Informação, a USP, a UFSC e a UFPE apresentam os maiores percentuais de disciplinas (18,63\%, 17,83\% e $17,14 \%$, respectivamente). São comuns as disciplinas de catalogação ou 
representação descritiva, linguagens documentárias e representação temática. Com relação a esta última, em 7 casos observou-se a especificidade da disciplina de indexação; nos demais cursos esse processo estava previsto na ementa da disciplina de representação temática.

As disciplinas dessa área ocorrem em geral com denominação similar, sendo dividas em I, II e até III módulos. Apenas os cursos da USP, UFGRS e UFPE oferecem - no primeiro, segundo e primeiro semestres, respectivamente - uma disciplina de Introdução à Organização da Informação que aborda aspectos históricos e teóricos sobre a análise documentária e antecede 0 estudo dos códigos, instrumentos e sistemas. Ressaltamos que somente a USP e a UNESP oferecem matéria voltada aos estudos linguísticos de organização da informação: Linguística Documentária (USP) e Elementos Lógicos e Linguísticos em Organização e Representação do Conhecimento (UNESP). Ambas abordam teorias da linguagem e da terminologia voltadas principalmente ao estudo da construção de linguagens documentárias.

$\mathrm{Na}$ área de Organização e Tratamento da Informação percebe-se, na média geral, uma carga horária maior com relação às outras; o mesmo pode ser percebido com relação às áreas de Gestão de Unidades de Informação e Pesquisa. Na realidade, a área de Organização e Tratamento tem um lugar importante no universo da Biblioteconomia e Ciência da Informação "dada sua natureza mediadora entre a produção e o uso da informação." (GUIMARÃES, 2008). Nesse sentido, essa carga horária se justifica.

A área de Gestão de Unidades de Informação é a que apresenta a maior variedade de disciplinas e denominações. Pode-se afirmar que isso ocorre devido à amplitude dos temas relacionados à gestão e à diversidade dos processos organizacionais. Têm-se a gestão de recursos humanos e financeiros, marketing, planejamento, empreendedorismo, análise organizacional, entre outros tópicos. Em cada curso, esses tópicos aparecem ou não de forma específica, gerando algumas vezes uma disciplina com denominação particular. Nesse sentido, a análise dessa área precisa ser realizada juntamente com a análise dos conteúdos programáticos de cada disciplina para que seja possível perceber de forma mais consistente qual a 
carga horária dedicada a cada conteúdo. Essa análise, essencialmente qualitativa, poderá ser realizada em estudo complementar.

A Gestão da Informação representa, entre os currículos das escolas analisadas, o terceiro lugar entre as áreas curriculares. Comparativamente, em um estudo que analisou o perfil dos professores de Biblioteconomia das escolas brasileiras e as disciplinas ministradas nesses cursos, a área de Gestão da Informação apresenta maior carga horária (CUNHA; DEBALLI, 2013).

Todos os cursos apresentam a disciplina de desenvolvimento de coleções, ainda que com terminologias distintas (gestão de estoques informacionais, gestão de coleções, etc.). O curso da UFMA oferece, como obrigatória, disciplina que aborda a editoração.

A UFSC, UFMA e UDESC apresentam disciplinas relacionadas à prática arquivística denominadas, respectivamente, Gestão de Documentos, Arquivística, Gestão de Documentos em Arquivos. Nesse contexto, percebe-se a intenção em integrar os cursos de Biblioteconomia e Arquivologia, sendo que a UFSC oferece ainda disciplinas optativas em comum para os dois cursos, assim como a UNESP, que declara no seu Plano Pedagógico a intenção de manter essa integração entre os cursos por meio do oferecimento de disciplinas comuns.

$\mathrm{Na}$ área de Recursos e Serviços de Informação, a UFSC é a que dedica maior carga horária em disciplinas obrigatórias, somando 15,29\%. Quase todos os cursos oferecem pelo menos uma disciplina específica de estudos de usuários, com exceção da UFPE. O estudo de fontes de informação ocorre em todos os cursos, porém com denominações variadas, como: Fontes de Informação I e II (UFSC), Fontes Gerais de Informação (UFRGS), Informação Especializada (UFRGS), Recursos Informacionais I e II (USP), Fontes e Disseminação da Informação I e II (UFAL), entre outras.

Quanto ao estudo dos serviços de referência observa-se uma pulverização do tema que é abordado, em alguns casos, dentro da disciplina fontes de informação, em outros casos dentro da disciplina de disseminação e uso da informação e outros ainda a disciplina é oferecida de forma específica, 
além daquelas de fontes e disseminação, como é o caso da UFSC, UFRGS, UDESC, UFSCAR e UFMA. A temática da recuperação da informação, no que tange à teoria e à prática, é abordada em disciplina específica pela UFSC, UDESC e UFPE. Nas demais universidades esse conteúdo é discutido dentro de outras disciplinas dessa área.

É importante ressaltar que a recuperação da informação tem uma estreita relação com a área de tecnologia, podendo ser alocada em ambas as áreas. Ao mesmo tempo em que a recuperação da informação é um serviço indispensável, é também uma prática atrelada ao conhecimento tecnológico no que tange ao funcionamento dos mecanismos de busca aliado ao conhecimento de elaboração de estratégias de busca. Neste estudo, consideramos a recuperação da informação como um tema relacionado à área de Recursos e Serviços de Informação. Dessa forma, deve-se considerar que o alinhamento das disciplinas de recuperação da informação à área de Serviços ou de Tecnologias dependerá da análise realizada para tal classificação. Um estudo apurado dos conteúdos programáticos pode elucidar essa questão.

$\mathrm{Na}$ área de Tecnologias da Informação a UFSC apresenta o menor percentual, 2,55\%, que assim como a USP (2,94\%), oferece apenas uma disciplina específica, de Informatização de Unidades de Informação, e Documentação e Informática, respectivamente. A UDESC, que apresenta o maior percentual nessa área $(11,17 \%)$ oferece as disciplinas de Gestão de Bibliotecas Digitais, Gerenciamento Eletrônico de Documentos, Tecnologias da Informação e Comunicação I, II e III além do Planejamento e Geração de Bases de Dados. Na realidade, é necessário lembrar que esse curso tem como foco a gestão da informação com forte ênfase em tecnologia. Os cursos da UFSC, USP, UFAL e UFMA não oferecem disciplinas específicas para estudo de bases de dados.

$\mathrm{Na}$ área de Pesquisa se observa maior uniformidade de carga horária entre as universidades, com exceção da UFAL que oferece a menor carga nessa área $(6,86 \%)$, sendo representada apenas pelas disciplinas de Metodologia de Pesquisa e TCC. Os demais cursos apresentam o TCC dividido em duas disciplinas distintas: projeto de TCC e elaboração de TCC; 
outras oferecem pelo menos uma disciplina de introdução à pesquisa em Biblioteconomia, além da metodologia de pesquisa, e as disciplinas de projeto e elaboração do TCC. Em oito casos, a normalização da documentação é estudada em disciplina própria e também em 8 casos é oferecida a disciplina de Estatística. A UNESP e a UFSCAR oferecem a disciplina de Bibliometria como obrigatória.

A delimitação da área de Formação Geral não é tarefa fácil, pois suas temáticas podem compor as áreas de formação específica dependendo do direcionamento de cada conteúdo. Um exemplo que pode ilustrar esse aspecto são as disciplinas de Administração as quais consideramos de formação geral. Trata-se de disciplinas não direcionadas às unidades de informação como por exemplo: Teoria Geral da Administração ou Introdução à Administração. Já as disciplinas que focam essas teorias no contexto das unidades de informação foram consideradas como componentes da área de Gestão. O mesmo ocorre com as disciplinas que abordam aspectos históricos, culturais e políticos do Brasil. Disciplinas de História do Brasil e Antropologia, por exemplo, são consideradas de formação geral. Já a história dos meios de comunicação e informação e das bibliotecas é enquadrada nos Fundamentos da Biblioteconomia e da Ciência da Informação, já que tratam diretamente do desenvolvimento e consolidação da profissão do bibliotecário. Ainda assim, foi necessária uma leitura das ementas para identificar essa diferenciação que muitas vezes não estava clara na denominação da disciplina.

Ocorre uma diferença significativa entre o curso com menor percentual de disciplinas nessa área, a UFPE com 1,22\%, e o maior percentual, a USP com $22,55 \%$. Nessa área os temas mais recorrentes são a comunicação e expressão verbal, a introdução à Sociologia, e a Filosofia centrada no estudo da lógica. Oferecem a disciplina Inglês Instrumental a UFSC, UNESP, UFSCAR, UFAL e UFMA. Ressaltamos também que a UDESC e USP são as únicas a abordarem em disciplina própria as temáticas relativas à área da Educação.

\section{CONSIDERAÇÕES FINAIS}

Inf. Inf Londrina, v. 23, n. 1, p. 290 - 310, jan./abr. 2018 http://www.uel.br/revistas/informacao/ 
Dada a variabilidade da distribuição de carga horária em cada área curricular conforme mostram os resultados da pesquisa, pode-se concluir que é possível estabelecer uma grade curricular para o curso de Biblioteconomia de forma bastante específica. Essa particularidade, que carece de um estudo mais aprofundado, é composta de distintos elementos: a formação do corpo docente, as características econômicas e sociais da região, entre outros.

Nesse contexto, reiteramos a relevância de se estar atento a não pensar o currículo de forma demasiado individualizada. Para tanto, é sensato estar a pardas discussões que ocorrem nas Associações de Ensino e Associações Profissionais tanto para atender à realidade atual quanto para modificá-la. Todavia, ressaltamos que esse estudo já é uma forma de dialogar com os demais cursos de Biblioteconomia do Brasil.

Em um ambiente em mutação permanente, a capacidade de aprender continuamente é essencial. Nesse sentido, no nosso entender, os responsáveis pela criação e manutenção dos cursos de Biblioteconomia devem estar atentos às demandas da sociedade, cada vez mais diversificadas, procurando suprir as necessidades identificadas por meio da oferta de profissionais conscientes, críticos e abertos a mudanças.

\section{LIMITAÇÕES DO ESTUDO}

A maior dificuldade encontrada na etapa de levantamento dos dados foi a diversidade com que cada universidade apresenta as informações do curso de Biblioteconomia em seu site. Consideramos este aspecto uma limitação pois em alguns casos não foi possível identificar de forma clara a estrutura curricular da universidade.

Em diversos casos, as informações constantes nos sites não diferenciavam a carga horária total de atividades complementares; assim, esta informação foi inserida na análise de forma geral, sem diferenciar as atividades complementares que compõem esse conjunto. Outro aspecto a destacar é que alguns currículos não apresentavam as ementas das disciplinas oferecidas por outros departamentos (ex: Inglês Instrumental, Introdução à Sociologia, etc.). 
Considerando a ampla gama de disciplinas optativas oferecidas nos cursos e, por conseguinte, um grande universo de dados e variáveis (cargahorária, áreas de conhecimento, etc.), julgamos que um estudo referente a essas disciplinas deve ser realizado em outra etapa. Por isso, esse estudo contemplou somente as disciplinas obrigatórias dos cursos de Biblioteconomia.

\section{REFERÊNCIAS}

ABECIN. O percurso da formação em biblioteconomia e ciência da informação no Brasil: uma trajetória integrada ao Mercosul. In: ENCUENTRO DE DIRECTORES, 8.; ENCUENTRO DE DOCENTES DE ESCUELAS DE BIBLIOTECOLOGÍA Y CIENCIAS DE LAINFORMACIÓN DEL MERCOSUR, 7. 2007, Valparaíso. Anais... Valparaíso: Universidad de Playa Ancha, 2007.

BRASIL. Lei n. 9.394, de 20 de dezembro de 1996. Estabelece as diretrizes e bases da educação nacional. Disponível em:

$<$ http://www.planalto.gov.br/ccivil_03/Leis/L9394.htm>. Acesso em: 07 mar 2018.

CASTRO, Cesar Augusto. Histórico e evolução curricular na área de Biblioteconomia no Brasil. In: VALENTIM, Marta Ligia Pomim (Org.). Formação do profissional da informação. São Paulo: Polis, 2002. p. 25-48.

CONSELHO FEDERAL DE BIBLIOTECONOMIA. Resolução n. 153, de 06 de março de 1976. Dispõe sobre o ensino de ética bibliotecária. Diário Oficial da União. Brasília, DF, 1976, p. 1407.

CONSELHO NACIONAL DE EDUCAÇÃO. Parecer CNE/CES N. 492/2001, de 3 de abril de 2001. Apresenta Diretrizes Curriculares Nacionais dos cursos de Filosofia, História, geografia, Serviço Social, Comunicação Social, Ciências Sociais, Letras, Biblioteconomia, Arquivologia e Museologia. Disponível em: $<$ http://portal.mec.gov.br/cne/arquivos/pdf/CES0492.pdf>. Acesso em: 07 mar 2018.

CUNHA, Miriam Vieira da. Las profesiones de la información: un escenario de câmbios. Ciencias de la Información, Cuba, v. 44, n. 1, 2013.

CUNHA, Miriam Vieira da; DEBALI, Juan Carlos. Quem forma o bibliotecário? Perfil dos professores dos cursos de Biblioteconomia brasileiros. In: ENCONTRO IBÉRICO EDICIC, 6., 2013, Porto, Portugal. Anais... Porto: Faculdade de Letras da Universidade do Porto, 2013.

GUIMARÃES, José Augusto Chaves. A dimensão teórica do tratamento temático da informação e suas interlocuções com o universo científico da 
International Society for Knowledge Organization (ISKO). Revista Iberoamericana de Ciência da Informação, Brasília, v. 1, n. 1, 2008, p. 77-99.

GUIMARÃES, José Augusto Chaves. Estudos curriculares em Biblioteconomia no Mercosul: reflexões sobre uma trajetória. In: VALENTIM, Marta Ligia Pomim. (Org.). Formação do profissional da informação. São Paulo: Polis, 2002. Cap. 3.

RODRIGUES, Mara Eliane Fonseca. A formação profissional em Biblioteconomia: superando limites e construindo possibilidades. Encontros Bibli, Florianópolis, n.13, p.13-24, 2002.

RODRIGUES, Mara Eliane Fonseca; CUNHA, Miriam Vieira da. O percurso da formação em Biblioteconomia e Ciência da Informação no Brasil: uma trajetória integrada ao Mercosul. In: ENCUENTRO DE DIRECTORES, 8.; ENCUENTRO DE DOCENTES DE ESCUELAS DE BIBLIOTECOLOGÍA Y CIENCIAS DE LAINFORMACIÓN DEL MERCOSUR, 7., 2007, Valparaíso. Anais... Valparaíso: Universidad de Playa Ancha, 2007.

SOUZA, Francisco C. A contribuição da ABEBD para a configuração política e ideológica das Diretrizes Curriculares Nacionais (DCN) do Curso de graduação em Biblioteconomia implantadas a partir de 2001.

Florianópolis, 2011. Relatório de Pesquisa. Disponível em: <http://eprints.rclis.org/19807/1/Relat\%C3\%B3rio\%20\%20A\%20contribui\%C3\%A7\%C3\%A3o\%20da\%20ABEBD\%20para\%20a\%20c onfigura\%C3\%A7\%C3\%A30\%20politica\%20das\%20DCNs.pdf>. Acesso em: 07 mar 2018. 


\section{ANEXO}

Quadro 1 - Universidades Federais e Estaduais que oferecem curso de Biblioteconomia INSTITUICOOES POR REGIÃO E ESTADO

\begin{tabular}{|c|c|c|}
\hline \multirow{2}{*}{\multicolumn{3}{|c|}{ INSTITUIÇŌES POR REGIÁO E ESTADO }} \\
\hline & & \\
\hline & RS & \\
\hline 1. & Universidade Federal do Rio Grande do Sul & UFRGS \\
\hline 2. & Universidade Federal do Rio Grande & FURG \\
\hline & 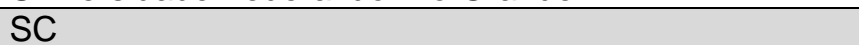 & \\
\hline 3. & Universidade do Estado de Santa Catarina & UDESC \\
\hline 4. & Universidade Federal de Santa Catarina & UFSC \\
\hline & PR & \\
\hline 5. & Universidade Estadual de Londrina & UEL \\
\hline \multicolumn{3}{|c|}{ REGISÃO SUDESTE } \\
\hline & SP & \\
\hline 6. & Universidade de São Paulo & USP \\
\hline 7. & Universidade Estadual Paulista Júlio de Mesquita Filho & UNESP \\
\hline 8. & Universidade Federal de São Carlos & UFSCAR \\
\hline & RJ & \\
\hline 9. & Universidade Federal do Estado do Rio de Janeiro & UNIRIO \\
\hline & MG & \\
\hline 10 & Universidade Federal de Minas Gerais & UFMG \\
\hline & ES & \\
\hline 11 & Universidade Federal do Espírito Santo & UFES \\
\hline \multicolumn{3}{|c|}{ REGIÃO CENTRO-OESTE } \\
\hline & MT & \\
\hline 12 & Universidade Federal de Mato Grosso & UFMT \\
\hline & GO & \\
\hline 13 & Universidade Federal de Goiás & UFG \\
\hline & DF & \\
\hline 14 & Universidade de Brasília & UNB \\
\hline \multicolumn{3}{|c|}{ REGIÃO NORDESTE } \\
\hline & BA & \\
\hline 15 & Universidade Federal da Bahia & UFBA \\
\hline & SE & \\
\hline 16 & Universidade Federal de Sergipe & UFS \\
\hline & $\mathrm{AL}$ & \\
\hline 17 & Universidade Federal de Alagoas & UFAL \\
\hline & $\mathrm{PE}$ & \\
\hline 18 & Universidade Federal de Pernambuco & UFPE \\
\hline & PB & \\
\hline 19 & Universidade Federal da Paraíba & UFPB \\
\hline & $\mathrm{RN}$ & \\
\hline 20 & Universidade Federal do Rio Grande do Norte & UFRN \\
\hline & $\mathrm{CE}$ & \\
\hline 21 & Universidade Federal do Ceará & UFC \\
\hline & $\mathrm{PI}$ & \\
\hline 22 & Universidade Estadual do Piauí & UESPI \\
\hline & MA & \\
\hline 23 & Universidade Federal do Maranhão & UFMA \\
\hline
\end{tabular}

Inf. Inf Londrina, v. 23, n. 1, p. 290 - 310, jan./abr. 2018. http://www.uel.br/revistas/informacao/ 


\begin{tabular}{|r|l|l|}
\hline \multicolumn{2}{|c|}{ REGIÃO NORTE } \\
\hline & PA & \\
\hline 24 & Universidade Federal do Pará & UFPA \\
\hline & AM & \\
\hline 25 & Universidade Federal do Amazonas & UFAM \\
\hline & RD & \\
\hline 26 & Universidade Federal de Rondônia & UNIR \\
\hline
\end{tabular}

\title{
COMPARATIVE STUDY OF SYLLABUS OF LIBRARIANSHIP COURSES IN BRAZIL
}

\begin{abstract}
Introduction: The society constitutes of an organic movement in its many dimensions - cultural, professional, educational, etc. - thus, it is necessary to rethink and give a new signification to the Librarianship courses' syllabi based on this social evolution. Objective: The study's objective is to survey information about Brazilian universities Librarianship courses' syllabi so that it develops an overview of their current situation. Methodology: Initially, 26 courses of federal and state universities were selected, but only nine universities that presented the necessary information for this research in their websites were considered. The courses' syllabi were analyzed in relation to the subject areas proposed for Mercosul countries Librarianship courses. Results: We found the area that presents the longest hours of study in mandatory disciplines is the General Formation, with $16,56 \%$. The area with shorter hours of study of mandatory disciplines is Information Technology, with 5,94\%. We verified also that the distribution of hours of study in each subject area presents a wide variety, from the different contexts of the analyzed universities. Conclusion: Thus, we emphasize the necessity of not to think the courses' syllabus as a too individualized one. Therefore, it is essential to be aware of the social demands both to attend and also to modify them.
\end{abstract}

Descriptors: Librarianship. Syllabus. Brazil.

\section{ESTUDIO COMPARATIVO DE LOS CURRÍCULOS DE LOS CURSOS DE BIBLIOTECOLOGÍA EN BRASIL.}

\section{RESUMEN}

Introducción: La sociedad se constituye en un movimiento orgánico en sus diversas dimensiones - cultural, profesional, educativo, etc. - por lo tanto, es esencial que los currículos de los cursos de Bibliotecología sean revisados y reinterpretados a partir de esta evolución social. Objetivo: Este estudio tiene como objetivo recoger información sobre el currículo de los cursos de Bibliotecología de las universidades brasileñas con el fin de desarrollar una visión general de la situación actual de estos cursos. 
Metodología: Inicialmente, se seleccionaron los 26 cursos de las universidades brasileñas federales y estatales, sin embargo, se consideran sólo las nueve universidades que ofrecen en sus sitios web la información necesaria para el estudio. Los currículos fueron analizados desde las áreas curriculares propuestas para los cursos de Bibliotecología de los países del Mercosur. Resultados: Constatámos que el area que tiene la más grande carga horaria de materias obligatorias es lo de Formación General, con $16,56 \%$. El área con la representación más baja es la Tecnología de la Información, con 5,94\%. También observamos que la distribución de la carga horaria en cada área curricular es bastante variada, desde diferentes contextos de las universidades analizadas. Conclusión: En este sentido, señalamos la necesidad de no pensar -se en el currículo demasiado individualmente. Por lo tanto, es prudente estarmos cientes de las demandas sociales tanto para cumplir con la realidad actual cuanto para cambiarla.

Descriptores: Bibliotecología. Estrutura curricular. Brasil. 